\title{
Pascal Quignard. Littérature hors frontières, Irène Fenoglio et Verónica Galíndez-Jorge
}

\section{Stefano Genetti}

\section{(2) OpenEdition}

1 Journals

\section{Edizione digitale}

URL: http://journals.openedition.org/studifrancesi/1474

DOI: $10.4000 /$ studifrancesi. 1474

ISSN: 2421-5856

\section{Editore}

Rosenberg \& Sellier

\section{Edizione cartacea}

Data di pubblicazione: 1 décembre 2015

Paginazione: 634

ISSN: 0039-2944

\section{Notizia bibliografica digitale}

Stefano Genetti, «Pascal Quignard. Littérature hors frontières, Irène Fenoglio et Verónica GalíndezJorge», Studi Francesi [Online], 177 (LIX | III) | 2015, online dal 01 décembre 2015, consultato il 08 janvier 2021. URL: http://journals.openedition.org/studifrancesi/1474 ; DOI: https://doi.org/10.4000/ studifrancesi. 1474

Questo documento è stato generato automaticamente il 8 janvier 2021.

\section{(c)}

Studi Francesi è distribuita con Licenza Creative Commons Attribuzione - Non commerciale - Non opere derivate 4.0 Internazionale. 


\title{
Pascal Quignard. Littérature hors frontières, Irène Fenoglio et Verónica Galíndez-Jorge
}

\author{
Stefano Genetti
}

\section{NOTIZIA}

Pascal Quignard. Littérature hors frontières, sous la direction de Irène FENOGLIO et Verónica GALÍNDEZ-JORGE, Paris, Hermann, 2014, pp. 212.

1 Bordi, margini, soglie: tra linee di demarcazione e sconfinamenti si muovono gli atti del convegno tenutosi a San Paolo del Brasile il 7 e l'8 ottobre 2013. È stata tra l'altro l'occasione per presentare il programma di traduzioni in portoghese di testi di Quignard (Ruth SILVIANO BRANDÃo, Traduire "Le Nom sur le bout de la langue", pp. 169-176) e per sottolineare la centralità, nella pratica quignardiana, dell'attività traduttiva, nonché dell'idea di traslazione - vale a dire di "metafora" etimologicamente intesa non solo come scambio linguistico-culturale ma anche come perdita dei confini spaziotemporali dettata dall'indissociabilità di lettura e scrittura (Verónica GALÍNDEZ-JORGE, Lec(ri)ture, pp. 73-89). A questo proposito, volentieri si coglie l'opportunità di segnalare, sul versante italiano, la traduzione di Bute firmata da Angela Peduto e pubblicata, nel dicembre 2014, dalla casa editrice astigiana Analogon.

Incentrati sulla porosità delle frontiere tra i generi letterari (Mireille CALLE-GRUBER, Passages des genres. Stases et extases dans les récits de Pascal Quignard, pp. 91-107), le categorie estetiche (Chantal LAPEYRE-DESMAISON, Pascal Quignard, un baroque contemporain, pp. 109-129) o le istanze psicanalitiche (Yolanda VILELA, Les "sordidissimes" et la question de l'objet, pp. 153-167, sulla nozione lacaniana di objet), gli interventi di San Paolo sono incorniciati da un inedito di Pascal QUIGNARD (Le hors frontière, pp.9-17), dove la meditazione sulla letteratura come secessione «hors cité» (p. 13) e dis-integrazione sociale assume accenti "politici" che risuonano anche in Sur l'idée d'une communauté de 
solitaires (variazioni sulle rovine di Port-Royal edite nella collana «Arléa-Poche» nel marzo 2015), e dalla stimolante sezione «S'initier à la lecture de Pascal Quignard», che riunisce i commenti di quattro studenti e le relative reazioni dell'autore.

3 Se in La singularité hors les frontières de l'identité (pp. 43-71), Irène FENOGLIO si interroga, sulla scia di Benveniste e dello psicanalista britannico Adam Phillips, sull'espressione di una soggettività, al contempo solitaire e solidaire, svincolata dalla definizione di un'entità identitaria univoca, in Humain-animal: l'ultime frontière (pp. 21-41), Jean-Louis PAUTROT ripercorre un'ampia tradizione poetico-filosofica che da Descartes arriva fino a Nietzsche, ai Surrealisti, a Bataille e Derrida: tramite un'efficace ricapitolazione dei motivi - memoria antropo-zoologica e bestiario, predazione e anthropomorphose - che in Quignard concorrono a destabilizzare il logo-antropocentrismo, sottolinea le molteplici «figures de vivance» (p. 24) di cui la valorizzazione dell'animale nell'umano è portatrice.

4 Un cenno a parte merita la riflessione metacritica intitolata Le visage troué du critique quignardien (pp. 131-151) dove Camilo BogoYA traccia il profilo - o, meglio, i profili - del commentatore dell'opera di Quignard distinguendo tre tipologie: il «critique obéissant», il «critique transgresseur» e il «critique artiste». Mobilitando i concetti di autorità e autorialità, di circolo ermeneutico e «sidération de la lecture» (p. 135), egli individua nella sottomissione o identificazione, nella distanziazione e nella ri-creazione tre modelli ricorrenti di ricezione. Mette così in rilievo il rischio del mimetismo interpretativo, se non della ripetizione, insito in un'opera che, tra autoreferenzialità e riscrittura, forgia e dispiega un lessico speculativo che anticipa e deprogramma il discorso critico cui pure fa appello, la frontiera e lo sconfinamento in questione essendo, in questo caso, quelli tra discorso e metadiscorso letterario all'interno dell'opera stessa e nel dialogo che si instaura con il lettore, a iniziare dal lettore "professionista". 